\title{
Classification of Aerosol Types over Ghardaia, Algeria, Based on MODIS Data
}

\author{
Zaiani Mohamed, Djafer Djelloul, and Chouireb Fatima
}

\begin{abstract}
Anthropogenic and natural aerosols are important atmospheric constituents that significantly contribute to the Earth's radiation budget but remain uncertainties due to the poor understanding of their properties and their direct effects on scattering and absorption of solar radiation and their ability to stay in atmosphere for a very short time. The aerosol properties retrieved from the Moderate Resolution Imaging Spectroradiometer (MODIS) measurements collected during the period 2004-2012 are used for the first time to identify the types of aerosols over Ghardaia city. Two parameters are used for aerosol analyses, the Aerosol Optical Thickness (AOT) and the Angstrom exponent $(\alpha)$. The obtained results show different types of aerosols, representing biomass-burning, urban, maritime and dust aerosols. The aerosol type discrimination shows a clear domination of urban aerosols compared to maritime, dust and biomass-burning aerosols. They represent respectively the fractions of $54 \%, 32 \%, 13 \%$ and $1 \%$.
\end{abstract}

Index Terms-Aerosol optical thickness, aerosols, dust aerosols, urban aerosols, maritime aerosols, biomass-burning aerosols, angstrom exponent, angstrom coefficient.

\section{INTRODUCTION}

Atmospheric aerosols are defined as suspended particles in the atmosphere in liquid or solid phase. The presence of aerosols in atmosphere can affect our weather and climate because they change the amount of sunlight reaching Earth's surface [1]. The aerosols have different size distributions, shapes, and residence times. They originate from different sources such as gases condensation and action of wind on Earth's surface.

The Aerosol optical Thickness which is a wavelength dependent is a measure of the total extinction of sunlight due to scattering and absorption by aerosols [2], [3]. In the case of climate and weather, the presence of solid particles in the Earth's atmosphere has important consequences on the transmission of solar radiation and on the nature of the radiation that reaches the ground [4].

The absorption of solar energy by a layer of aerosols increases the radiative heating of the atmosphere and decreases the amount of energy reaching the ground surface.

The scattering by aerosols increases the amount of radiation which is reflected by the atmosphere into space and increases the downward flux of diffuse radiation at the Earth's surface [5]. In fact, there is a simple relationship

Manuscript received September 12, 2015; revised December 25, 2015.

Zaiani Mohamed and Djafer Djelloul are with Unité de Recherche Appliquée en Energies Renouvelables, URAER, Centre de Développement des Energies Renouvelables, CDER, 47133, Ghardaia, Algeria (e-mail: mohamed_zaiani@hotmail.fr, adjafer@gmail.com).

Chouireb Fatima is with Faculté de Technologie, Université de Laghouat, Algeria (fatimachouireb@yahoo.com). between the Aerosol Optical Thickness $(\tau)$ and the percentage of transmission given by [6]:

$$
\text { transmission }=100 \times e^{-\tau}
$$

Related to these effects, aerosols types classification is important because these effects are different from one type of aerosols to another. For this reason, there were many studies performed to classify aerosols by using retrieved aerosol algorithms that adopt the inversion procedure [7]. Aerosols originated from different sources exhibit highly different optical and physico-chemical properties in addition to be wavelength dependent [8]. The correlation between aerosol properties makes their characterization easier, although in the majority of cases a well-mixed aerosols types is rather difficult to be classified [9]. The most common scatter plot for the aerosols types discrimination is between AOT and the Angstrom Exponent $\alpha$ [10]. Other techniques have also been used such as the wavelength dependence of single scattering albedo (SSA), the correlation between Fine-mode fraction and SSA [11] and the correlation between absorption and extinction Angstrom exponent [12].

According to Ichoku [13] there are four main aerosol types that can be categorized in the atmosphere which are : biomass-burning aerosols, urban aerosols, maritime aerosols and dust aerosols. Each of these aerosols have different physiochemical, optical and radiative characteristics according to their origin. Certain aerosols types can interact with cloud droplets and therefore modifying their microphysical properties which will influence the radiative properties and precipitation processes. The relationship between AOT and Angstrom exponent can be used to classify aerosol types in a particular site. High values of AOT are affected by biomass burning, dust or urban aerosols where $\alpha$ values near zero correspond to sea spray and dust and values above 1.5 indicate significant presence of smoker or urban aerosols [14].

The objective of the present work is to identify and classify the aerosols types over Ghardaia city using MODIS data for the period 2004-2012. To perform that two parameters are used for aerosols types identification witch are the Aerosol Optical Thickness and the Angstrom exponent. After a brief introduction in Section I, Section II describes the data used and aerosols proprieties. Section III talks about classification of aerosols where Section IV resumes and discusses the obtained results.

\section{USED DATA AND AEROSOl PropriETIES}

Our studied area is located in the center of the northern part of Algerian Sahara about $600 \mathrm{Km}$ far from the capital city 
(Fig. 1). It is considered as arid and dry area. Its geographical coordinates are: $+32^{\circ} 37^{\prime} \mathrm{N}$ in latitude, $+3^{\circ} 77^{\prime} \mathrm{E}$ in longitude and $430 \mathrm{~m}$ in altitude. This area is characterized by significant insolation rate. The mean annual global solar radiation measured on a horizontal plane exceeds 6000 $\left(\mathrm{Wh} / \mathrm{m}^{2}\right)$ and the sunshine duration is more than 3000 (hours/year) [4]. The present study uses $1 \mathrm{~km}$ resolution TERRA/MODIS of level 2.0 aerosol products (MOD04) of 9 years (2004-2012). This 2.0 level MODIS data will be used to retrieve the AOT, the Angstrom Exponent $(\alpha)$ and the Angstrom Coefficient $(\beta)$ values.

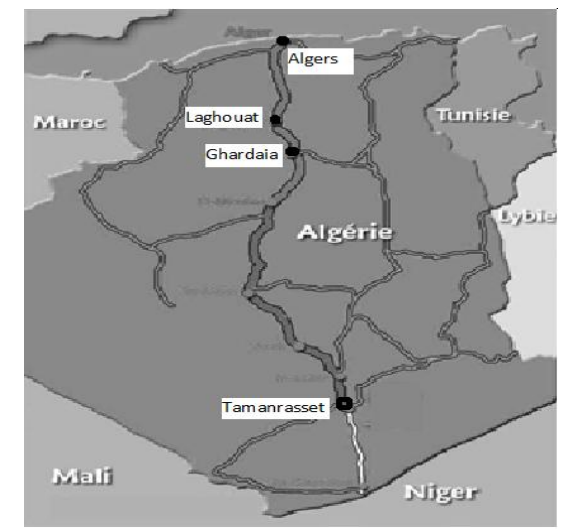

Fig. 1. Location of Ghardaia city.

The spectral dependence of AOT is used in this work to compute the Angstrom Exponent $\alpha$ values. A spectrally-averaged value of this exponent, which contains information about size of aerosols, can be obtained by fitting the Angstrom's formula [15], generally known as Angstrom's turbidity formula given by [16]:

$$
\tau=\beta \cdot \lambda^{-\alpha}
$$

The Angstrom Coefficient $\beta$ is one of the most widely used indicator of turbidity because it represents the amount of aerosols in the atmosphere in the vertical direction [17]. In addition, it represents the combined effects of both scattering and absorption caused by aerosols [18], [19]. The range of $\beta$ values varies between 0.0 and 0.5 and it may exceed the value 0.5 for a highly charged atmosphere.

The Angstrom exponent $\alpha$ is a reliable index of the size distribution of these aerosols. It is a good indicator of the dominant size of the atmospheric particles [20], [21]. This coefficient varies between 0 and 4 . When the aerosol particles are very small, of the order of the air molecules, $\alpha$ takes the value of 4 , and it approaches 0 for great particles. This indicator can be obtained by using the Angstrom exponential formula given by:

$$
\alpha=-\frac{\log \frac{\tau_{1}}{\tau_{2}}}{\log \frac{\lambda_{1}}{\lambda_{2}}}
$$

where $\tau_{1}$ and $\tau_{2}$ represent the AOT values at the wavelengths of $\lambda_{1}$ and $\lambda_{2}$ respectively.

\section{ClassificAtion OF AEROSOLS}

Ghardaia city is characterized by an urban environment but relatively influenced by nearby dust sources and industrial activities. We will characterize the aerosol types using the relationship between $\tau$ and $\alpha$ because of their strong wavelength dependence [10], [22], [23] using nine years of MODIS data [24].

As it has been stated before there are four main aerosols types that can be categorized in the atmosphere, which are biomass-burning aerosols, urban aerosols, maritime aerosols and dust aerosols. The most common method used to discriminate between them is based on the relationship between AOT and the Angstrom Exponent $\alpha$ values. The dust aerosols, due to the low $\alpha$ values, present the characteristic of high AOT in the longer wavelengths, which are then very useful to identify this type. As opposed to the dust aerosols, the urban and biomass burning aerosols are better identified by short wavelengths. According to the frequency distribution of $\alpha$, generally a threshold value is chosen to separate coarse and fine aerosols. Many studies in the literature used different thresholds of $\alpha$ versus $\tau$ for cluster analysis approach [25]-[28].

TABLE I: ClASSIFICATION OF AEROSOLS BASED ON AOT AND ANGSTROM EXPONENT $A$

\begin{tabular}{lcc}
\hline \hline Aerosols Types & AOT $(\tau)$ & $\begin{array}{c}\text { Angstrom Exponent } \\
(\alpha)\end{array}$ \\
\hline Maritime & $<0.3$ & $0.5-1.7$ \\
Dust & $>0.4$ & $<1.0$ \\
Urban & $0.2-0.4$ & $>1.0$ \\
Biomass-burning & $>0.7$ & $>1.0$ \\
\hline \hline
\end{tabular}

The classification criteria adopted in the present work is presented in Table I that summarizes the thresholds used with AOT and Angstrom exponent [21]. When $\alpha<1$ and AOT $>0.2$, it indicate the presence of dust. The occurrence of maritime aerosols usually occurred when $\alpha<1$ and AOT $<0.2$. When $1<\alpha<2$ and $0.2<$ AOT $<0.4$, this correspond to continental or urban aerosols. The presence of biomass-burning aerosols occurred when AOT $>0.7$ and $\alpha>1$.

\section{RESUlTS AND DISCUSSION}

Using the thresholds of Table I, the spatial distribution of Aerosols Optical Thickness values obtained from MODIS data are shown on Fig. 2. We note the presence of different amounts and sizes of aerosols that cover the sky of Ghardaia city and the spatial distribution of AOT lies between $31^{\circ} \mathrm{N}-35^{\circ} \mathrm{N}$ in latitude and between $2.5^{\circ} \mathrm{E}-4.5^{\circ} \mathrm{E}$ in longitude.

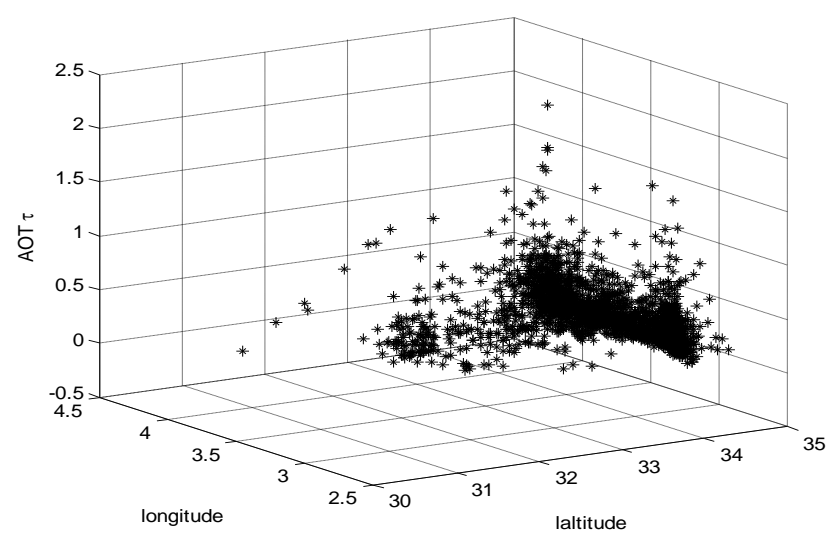

Fig. 2. Spatial distribution of aerosol optical thickness.

The diurnal patterns of AOT values at wavelength $0.47 \mu \mathrm{m}$ 
that correspond to dust absorption [29], are shown on Fig. 3(a). The daily averaged value of AOT varies between a minima of 0.1 and a maxima of 2.5 with a mean value of 0.17 . Fig. 3(b) shows the monthly mean values of AOT between 2004-2012. According to Fig. 3(b) we notice that AOT increased drastically from April to September and shows lower values form October to Mars. Fig. 4(a) shows the frequency distribution of the Angstrom exponent. We observe that $\alpha$ values vary between two main values which are 0.7 and 1.3 (see Fig. 4(b) ).

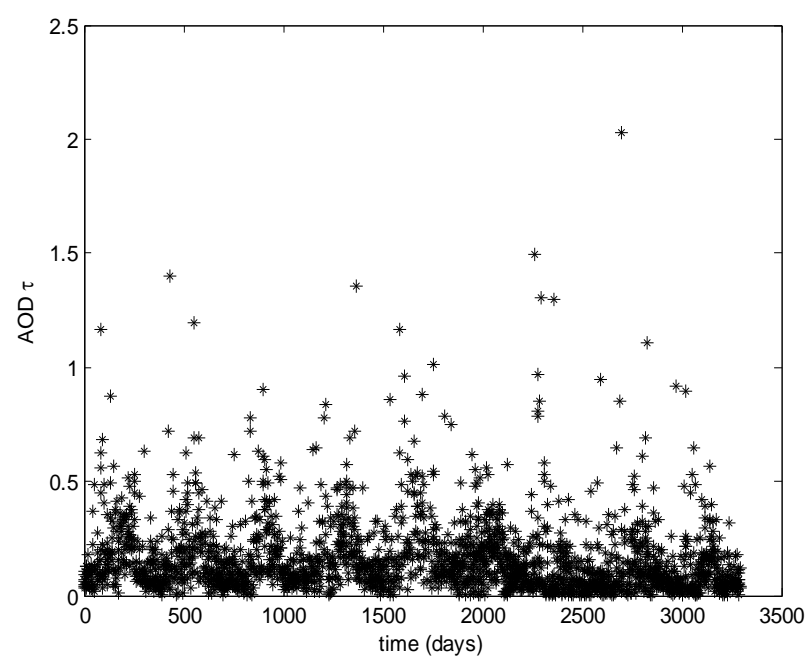

(a)

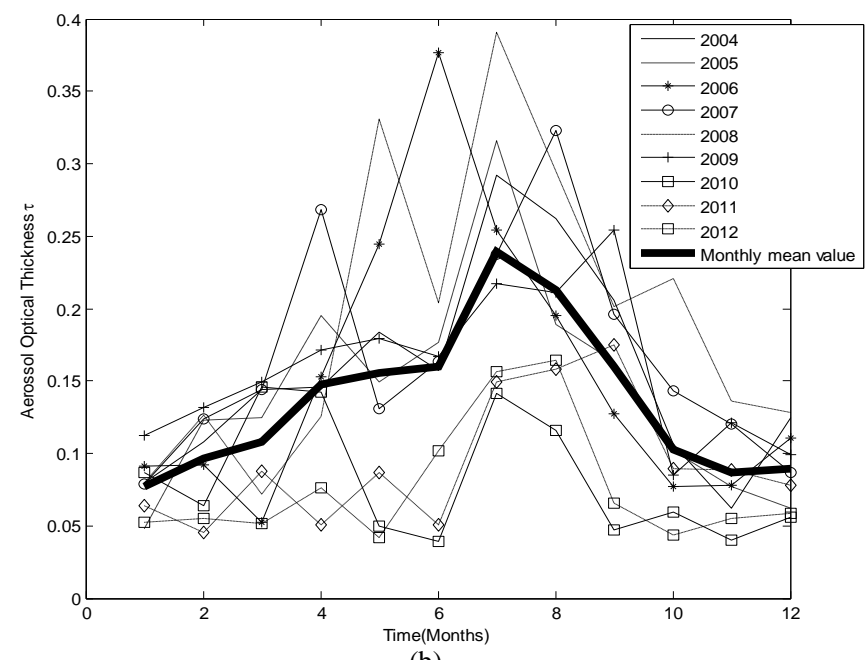

(b)

Fig. 3. (a) Trend of AOT during the period 2004-2012 period according to MODIS data, (b) Monthly mean values of AOT during the period 2004-2012.

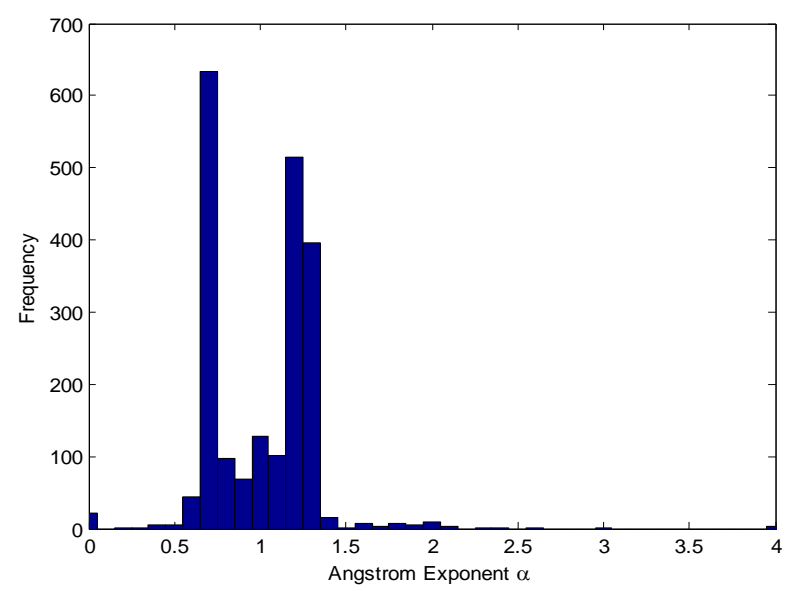

(a)

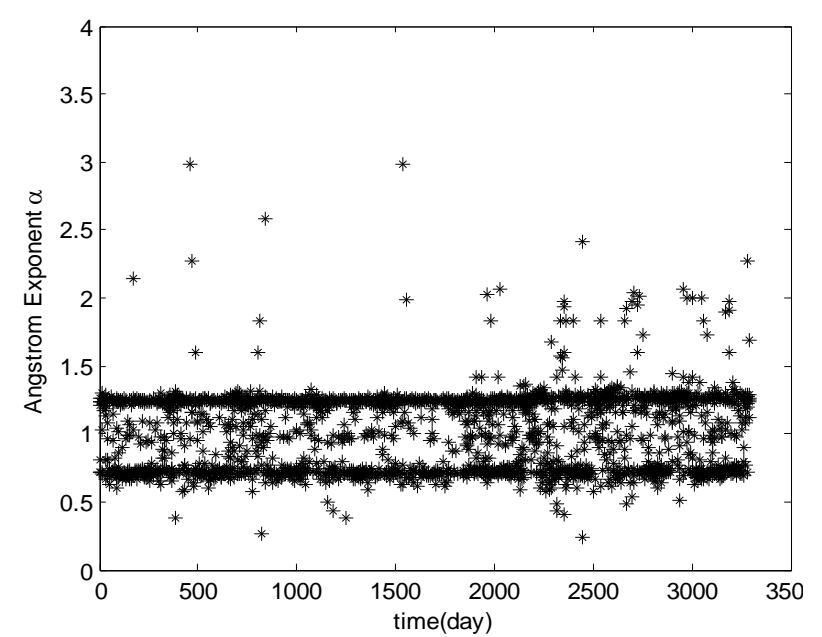

(b)

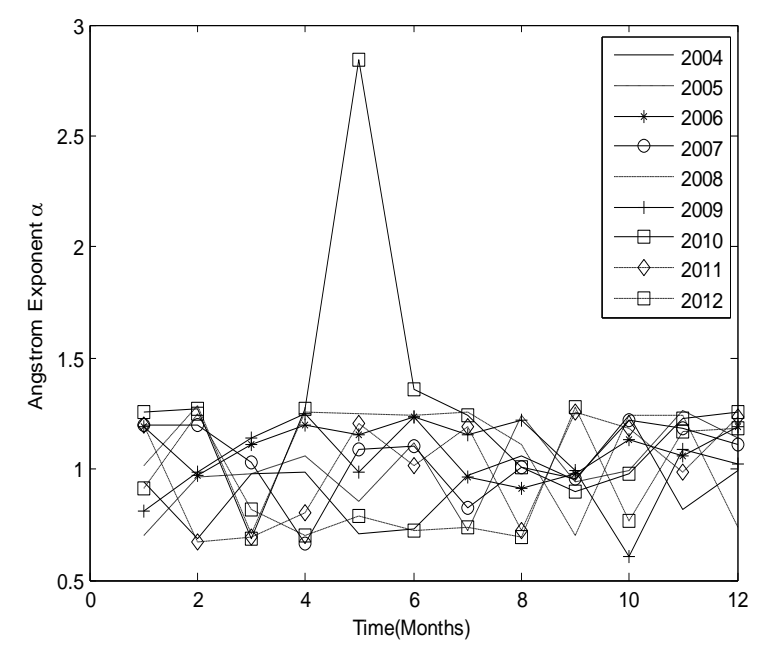

(c)

Fig. 4. (a) Frequency distribution of $\alpha$ during the period 2004-2012 using MODIS data, (b) Angstrom exponent values using MODIS data during the period 2004-2012, (c) Monthly mean values of Angstrom exponent using MODIS data during the period 2004-2012.

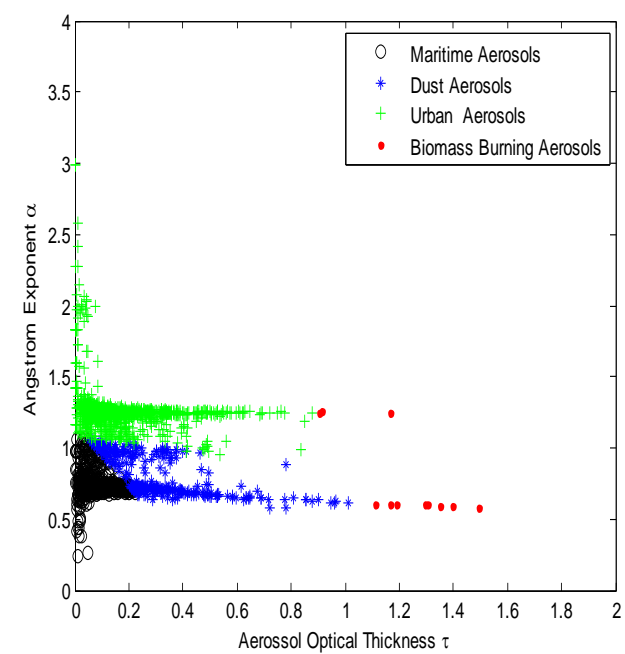

Fig. 5. Classification of aerosols types over Ghardaia city using nine years of MODIS data.

The Angstrom exponent as a function of AOT at $470 \mathrm{~nm}$ is shown on Fig. 5. We use the value of AOT at $550 \mathrm{~nm}$ to evaluate the value of $\alpha$ according to Equation 3. Using $\tau$ values versus $\alpha$ values, the different aerosol types are calculated and the results of classification using K-means clustering and Table I are illustrated by different symbols on Fig. 5. According to this Figure we have found that the 
presence of Urban, Maritime, Dust and Biomass Burning Aerosols represents $54 \%, 32 \%, 13 \%$ and $1 \%$ respectively. This means that the urban aerosols predominate the other types which is explained by the presence of many companies of crasher plants installed around the city.

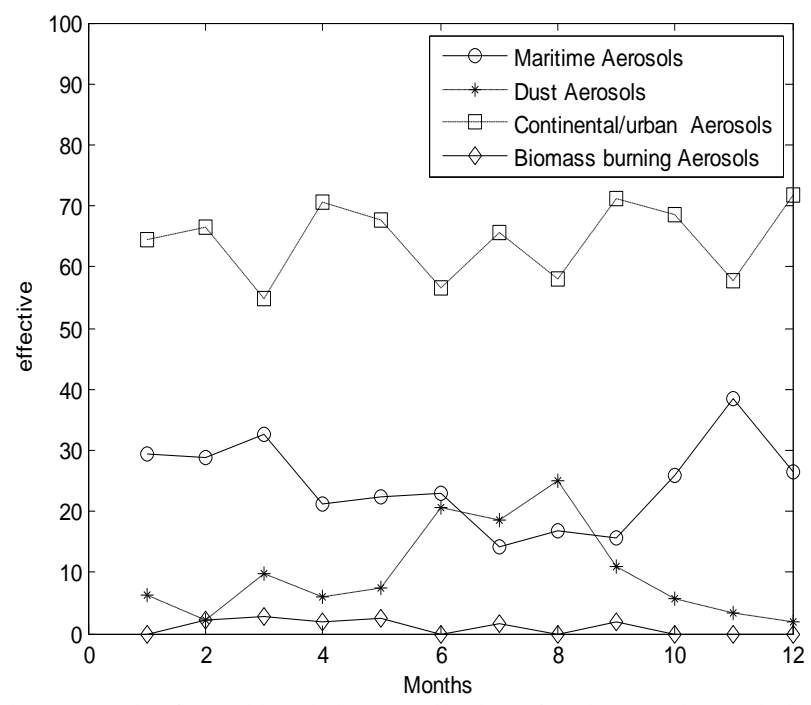

Fig. 6. Trends of monthly relative contribution of each aerosol type during the period 2004-2012.

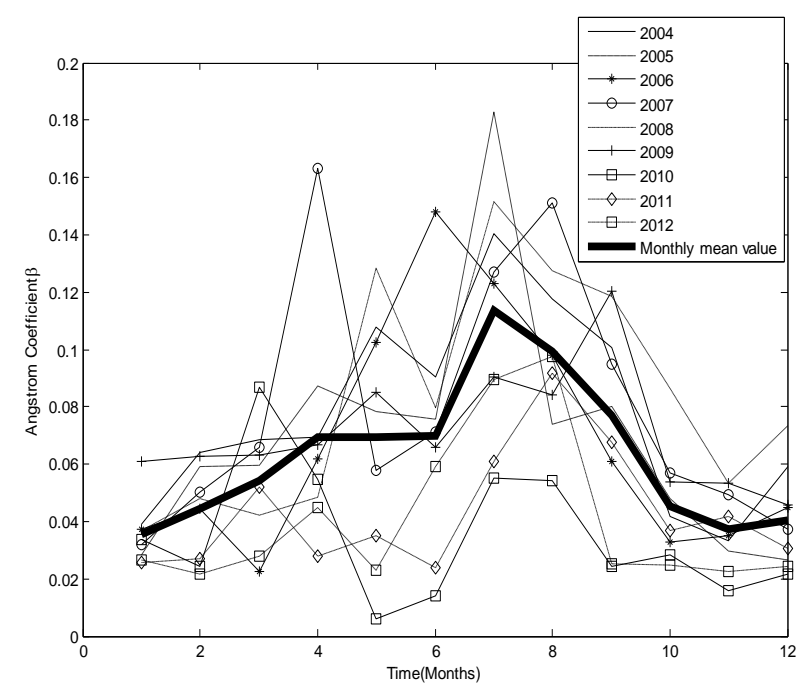

Fig. 7. Angstrom coefficients values using MODIS data during the period 2004-2012.

The trends of monthly relative contribution of each aerosol type during the period 2004-2012 are shown on Fig. 6.

We notice that the mean percentage of urban aerosols predominate the other types. One particular result that can be noticed is that the dust aerosols overhead the maritime aerosols between June and September. This results can be explained by a hot summer climate and winds of the south sectors (Sirocco) that characterize the region of Ghardaiia. This kind of winds brings with them particles of dust and sand [19]. This phenomena can be proved by the values of the Angstrom coefficient $(\beta)$ calculated using equation (2) (see Fig. 7) that shows maximum values between May and September which is the same behavior found by empirical models by Djafer and Irbah [19].

\section{CONCLUSIONS}

In the present work we have identified and classified the aerosols types over Ghardaia city using MODIS data for the period 2004-2012. To perform this work we have used the most common method based on the Aerosol Optical Thickness (AOT) and the Angstrom Exponent $(\alpha)$ values.

We have found that the daily averaged value of AOT varies between a minima of 0.1 and a maxima of 2.5 with a mean value of 0.17 and increased drastically from April to September and shows lower values form October to Mars.

Using $\tau$ values versus $\alpha$ values, we have calculated and classified the aerosol types using K-means clustering and appropriate thresholding. Results show that the presence of Urban, Maritime, Dust and Biomass Burning Aerosols represents 54\%, 32\%, $13 \%$ and $1 \%$ respectively, which means that the urban aerosols predominate the other types. This is explained by the presence of many companies ofcrasher plants installed around the city.

Investigating deeply the trends of the monthly relative contribution of each aerosol type we noticed that dust aerosols overhead the maritime aerosols between June and September which is explained by the hot summer climate and winds of the south sectors (Sirocco) that characterize the region of Ghardaiia during this period.

\section{REFERENCES}

[1] C. J. Wehrli, "Remote sensing of aerosol optical depth in a global surface network," ETH Zurich, Zurich, Switzerland, 2008.

[2] D. G. Hadjimitsis et al., "Applications of satellite remote sensing and GIS to urban air-quality monitoring: Potential solutions and suggestions for the Cyprus area," in Proc. 6th International Conference on Urban Air Quality, 2007, p. 144.

[1] M. A. Alghoul et al., "Impact of aerosol optical depth on solar radiation budget," presented at the 3rd WSEAS Int. Zaiani Mohamed, Djafer Djelloul, and Chouireb Fatima.

[2] M. Zaiani and D. Djafer, "Atmospheric turbidity study using ground and orbit data," International Journal of Latest Research in Science and Technology, vol. 3, issue 2, pp. 12-18, March-April 2014.

[3] A. J. Khairunnisa et al., "Retrievals of aerosol optical depth and angstrom exponent for identification of aerosols at Kuching, Sarawak," Advanced Materials Research, vol. 518-523, pp. 5734-5737, 2012.

[4] Aerosols. [Online]. Available: http://www.instesre.org/Aerosols/Aerosols_HTML.htm

[5] J. Kim et al., "Validation of aerosol type classification from satellite remote sensing," SPIE, vol. 7152 71520Q-1, 2008.

[6] O. Dubovik et al., "Variability of absorption and optical properties of key aerosol types observed in worldwide locations," J. Atmos. Sci., vol. 59, pp. 590-680, 2002.

[7] B. N. Holben et al., "Emerging ground-based aerosol climatology: aerosol optical depth from AERONET," Journal of Geophysical Research, vol. 106, no. 12, 2001.

[8] D. G. Kaskaoutis et al., "Aerosol climatology: Dependence of the Angström exponent on wavelength over four AERNET sites," Atmospheric Chemistry and Physics Discussion, vol. 7, pp. 7347-7397, 2007.

[9] J. Lee et al., "Characteristic of aerosol types from AERONET sunphotometer measurements," Atmos Environ, vol. 44, pp. 3110-3117, 2010.

[10] D. M. Giles et al., "Aerosol properties over the indo-gangetic plain: A mesoscale perspective from the TIGERZ experiment," J. Geophys. Res., vol. 116, 2011.

[11] C. Ichoku et al., "Global aerosol remote sensing from MODIS," Advances in Space Research, vol. 34, pp. 820-827, 2004.

[12] H. D. Kambezidis and D. G. Kaskaoutis, "Aerosol climatology over four AERONET sites: An overview," Atmospheric Environment, vol. 42, pp. 1892-1906, 2008.

[13] A. Angström, "The parameters of atmospheric turbidity," Tellus, vol. 16, pp. 64-75, 1964.

[14] T. Jiakui et al., "Aerosol retrieval over land by exploiting the synergy of terra and aqua modis data," Science in China Series D: Earth Sciences, vol. 49, no. 6, pp. 641-649, 2006.

[15] D. H. W. Li and J. C. Lam, "A study of atmospheric turbidity for Hong Kong," Renewable Energy, vol. 25, pp. 1-13, 2002.

[16] S. Janjai et al., "Determination of Angstrom's turbidity," Renewable Coefficient over Thailand Energy, vol. 28, pp. 1685-1700, 2003. 
[17] D. Djafer and A. Irbah, "Estimation of atmospheric turbidity over Ghardaïa city," Atmospheric Research, vol. 128, pp. 76-84, 2013.

[18] S. Basart et al., "Aerosol characterization in Northern Africa, Northeastern Atlantic, Mediterranean Basin and Middle East from direct-sun AERONET observations," Atmospheric Chemistry and Physics, vol. 9, pp. 8265-82, 2009

[19] C. Toledano et al., "Aerosol optical depth and Angstrom exponent climatology at El Arenosillo AERONET site (Huelva, Spain)," Quarterly Journal of the Royal Meteorological Society Q. J. R. Meteorol. Soc., vol. 133, pp. 795-807, 2007.

[20] D. G. Kaskaoutis et al., "Variations in the aerosol optical properties and types over the tropical urban site of Hyderabad, India," Journal of Geophysical Research, vol. 114, 2009.

[21] D. G. Kaskaoutis et al., "Extremely large anthropogenic aerosol component over the Bay of Bengal during winter season," Atmospheric Chemistry and Physics, vol. 11, pp. 7097-7117, 2011.

[22] Modis-atmos. [Online]. http://modis-atmos.gsfc.nasa.gov/MOD04_L2/index.html

[23] T. F. Eck et al., "Wavelength dependence of the optical depth of biomass burning, urban, and desert dust aerosols," Journal of Geophysical Research, vol. 104, pp. 333-31, 349, 1999.

[24] G. Pace et al., "Aerosol optical properties at Lampeduca (central Mediterranean)," Atmospheric Chemistry and Physics, vol. 6, pp. 697-713, 2006.

[25] M. C. R. Kalapureddy et al., "Identification of aerosol type over the Arabian Sea in the pre-monsoon season during the Integrated Campaign for Aerosols, Gases and Radiation Budget (ICARB)," Journal of Geophysical Research, vol. 114, 2009.

[26] B. Pathak et al., "Seasonal heterogeneity in aerosol types over Dibrugarh-North-Eastern India," Atmospheric Environment, vol. 47, pp. 307-315, 2012.

[27] X. Zhao, "Asian dust detection from the satellite observations of moderate resolution imaging spectroradiometer (MODIS)," Aerosol and Air Quality Research, vol. 12, pp. 1073-1080, 2012.

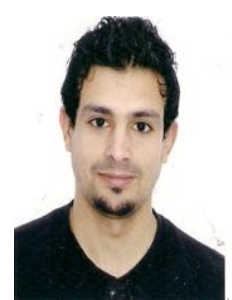

Mohamed Zaiani was born in Algeria on September 14, 1986. He got the M.SC degree in electronics from USTHB University in 2012. He got his engineer degree in electronics from Echole National Supérieure Polytechnique in 2009. He started working as researcher in Algerian renewable energy centre in May 2013 until now in renewable energy field. He has some research papers in international journals/conferences. Currently he is preparing his $\mathrm{Ph} . \mathrm{D}$ degree in modeling and predicting of solar radiation components.

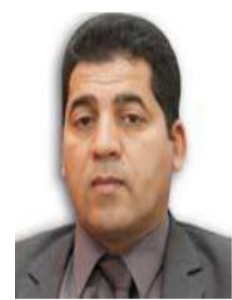

Djelloul Djafer was born and finished his primary and secondary studies in a small town in the south of Algeria (Metlili Chaanba). He attended the high School of Ghardaia where he succeeded in baccalaureate of mathematics. Then he attended the INELC institute (Algiers) were he obtained his engineer's degree in computer science in June 1990. After four years as teacher of mathematics, English language and computer science, he joined the Astronomy, Astrophysics and Geophysics Research Center (CRAAG) in October 1994 as researcher until October 2005 during which he got his magister degree in electronics. After that he attended the Aeronautic service (CNRS, Paris, France) where he obtained his doctorate degree and worked with the team of the spatial mission PICARD until its launching in June 2010. He soon attended the Renewable Energy Development Center (CDER, Algeria) as a researcher, and since August 2013 he was named director of the Unit of Applied Research in Renewable Energy situated in Algeria. He is a member in six international projects that concerns the solar physics and the relation between sun and earth atmosphere. 